\title{
Lung clearance index in adults with non-cystic fibrosis bronchiectasis
}

\author{
Sherif Gonem ${ }^{1,{ }^{*}}$, Alys Scadding ${ }^{1}$, Marcia Soares ${ }^{1}$, Amisha Singapuri ${ }^{1}$, Per Gustafsson², Chandra Ohri ${ }^{1}$, \\ Simon Range ${ }^{1}$, Christopher E Brightling ${ }^{1}$, lan Pavord ${ }^{1}$, Alex Horsley ${ }^{3,4}$ and Salman Siddiqui ${ }^{1}$
}

\begin{abstract}
Background: Lung clearance index $(\mathrm{LCl})$ is a measure of abnormal ventilation distribution derived from the multiple breath inert gas washout (MBW) technique. We aimed to determine the clinical utility of LCI in non-CF bronchiectasis, and to assess two novel MBW parameters that distinguish between increases in $\mathrm{LCl}$ due to specific ventilation inequality $\left(\mathrm{LCl}_{\text {vent }}\right)$ and increased respiratory dead space $\left(\mathrm{LCl} \mathrm{ds}_{\mathrm{ds}}\right)$.

Methods: Forty-three patients with non-CF bronchiectasis and 18 healthy control subjects underwent MBW using the sulphur hexafluoride wash-in technique, and data from 40 adults with CF were re-analysed. $\mathrm{LCl}_{\text {vent }}$ and $\mathrm{LCl}$ ds were calculated using a theoretical two-compartment lung model, and represent the proportional increase in $\mathrm{LCl}$ above its ideal value due to specific ventilation inequality and increased respiratory dead space, respectively.

Results: LCl was significantly raised in patients with non-CF bronchiectasis compared to healthy controls ( 9.99 versus $7.28, p<0.01$ ), and discriminated well between these two groups (area under receiver operating curve $=0.90$, versus 0.83 for forced expiratory volume in one second [\% predicted]). $\mathrm{LCl}, \mathrm{LCl}$ vent and $\mathrm{LCl}_{\text {ds }}$ were repeatable (intraclass correlation coefficient $>0.75$ ), and correlated significantly with measures of spirometric airflow obstruction.

Conclusion: $\mathrm{LCl}$ is repeatable, discriminatory, and is associated with spirometric airflow obstruction in patients with non-CF bronchiectasis. $\mathrm{LCl}_{\text {vent }}$ and $\mathrm{LCl}_{\mathrm{ds}}$ are a practical and repeatable alternative to phase III slope analysis and may allow a further level of mechanistic information to be extracted from the MBW test in patients with severe ventilation heterogeneity.
\end{abstract}

Keywords: Bronchiectasis, Lung clearance index, Ventilation heterogeneity

\section{Introduction}

Non-cystic fibrosis (CF) bronchiectasis is a chronic suppurative lung disease caused by a range of underlying conditions, which is increasing in prevalence [1], and which imposes a significant burden of morbidity and healthcare costs. In the United States alone, annual healthcare costs for bronchiectasis are estimated as $\$ 630$ million [2]. The causes of non-CF bronchiectasis are diverse, and include autoimmune disease, primary ciliary dyskinesia, allergic bronchopulmonary aspergillosis, immune deficiency and childhood respiratory infection [3]. Regardless of the underlying cause, the pathogenesis is thought to involve a vicious cycle of bacterial colonisation, neutrophilic

\footnotetext{
* Correspondence: sg330@le.ac.uk

${ }^{1}$ Institute for Lung Health, University of Leicester, Leicester, UK

${ }^{5}$ Respiratory BRU, Glenfield Hospital, Groby Road, Leicester LE3 9QP, UK

Full list of author information is available at the end of the article
}

airway inflammation, airway damage and mucus stasis [3]. The evidence base for the treatment of non-CF bronchiectasis lags well behind that of $\mathrm{CF}$, but this is expected to change in the near future as a number of non-CF bronchiectasis research registries and clinical trials are actively enrolling patients at present [4]. Such clinical trials will require robust physiological outcome measures in order to provide objective measures of improvement in lung function.

Multiple breath inert gas washout (MBW) is a technique for quantifying ventilation heterogeneity, the uneven distribution of ventilation [5]. This is an early feature of obstructive airway diseases such as asthma [6], chronic obstructive pulmonary disease [6] and cystic fibrosis (CF) [7]. A comprehensive standardisation document for the performance of inert gas washout has been recently published [8]. Lung clearance index 
(LCI) $[9,10]$ is the most commonly reported MBW parameter, and is defined as the cumulative expired volume at the point where end-tidal inert gas concentration falls below 1/40th of the original concentration, divided by the functional residual capacity (FRC). LCI has been shown to be both discriminatory and repeatable in patients with CF [7], and is increasingly being used as an outcome measure in clinical trials of CF therapies [11-13]. A recent study has shown that LCI is repeatable in patients with non-CF bronchiectasis, and correlates with computed tomography bronchiectasis severity scores [14].

Although LCI has been shown to be a robust and repeatable measurement in patients with $\mathrm{CF}$ and non-CF bronchiectasis, it also represents a simplification of the washout process since it is essentially determined by data points at the start and end of the washout curve only. From a theoretical standpoint, LCI may be increased by two distinct mechanisms, namely (i) unequal convective ventilation between relatively large lung units subtended by proximal conducting airways (convectiondependent inhomogeneity), and (ii) increased respiratory dead space, which is thought to be underpinned by diffusion-dependent gas mixing inefficiencies (diffusionconvection-dependent inhomogeneity) [15]. The only published method for separating out these mechanisms is the analysis of phase III slopes, yielding the parameters $S_{\text {cond }}$ (conductive ventilation heterogeneity index) and $S_{\text {acin }}$ (acinar ventilation heterogeneity index) [16]. This technique was developed from elegant clinical and modelling studies in healthy adult subjects [17]. However, the use of these parameters is problematic in patients with the most severe ventilation heterogeneity, such as those with advanced CF lung disease [18], both from a practical standpoint (the requirement for controlled $1 \mathrm{~L}$ breaths) and because the modelling may not be directly applicable in those with severe ventilation heterogeneity. To overcome this, modified versions of these parameters ( $\mathrm{S}_{\text {cond }}{ }^{*}$ and $\left.\mathrm{S}_{\text {acin }}{ }^{*}\right)$ have recently been proposed for use in such patients [19]. There remains a need however for a reliable and repeatable method of extracting mechanistic information from washout curves, which has been developed for, and can be applied in, those with more severe disease.

The primary aim of this study was to determine whether or not ventilation heterogeneity is a significant feature of non-CF bronchiectasis, and whether LCI may have potential as an outcome measure in this group of patients. A further aim of the study was to extend currently available measures of ventilation heterogeneity by developing novel parameters that would distinguish between specific ventilation inequality $\left(\mathrm{LCI}_{\mathrm{vent}}\right)$ and increased respiratory dead space $\left(\mathrm{LCI}_{\mathrm{ds}}\right)$ as a cause of increased LCI. $\mathrm{LCI}_{\text {vent }}$ and $\mathrm{LCI}_{\mathrm{ds}}$ would be expected to probe similar mechanisms of ventilation heterogeneity to $S_{\text {cond }}$ and $S_{\text {acin }}$, respectively, but without the potential drawbacks of phase III slope analysis, and with the advantage of being directly linked to LCI.

We hypothesised that:

i) Non-CF bronchiectasis is characterised by increased $\mathrm{LCI}, \mathrm{LCI}_{\mathrm{vent}}$ and $\mathrm{LCI}_{\mathrm{ds}}$ compared to healthy control subjects.

ii) LCI is related to other measures of disease severity in $\mathrm{CF}$ and non-CF bronchiectasis, namely the degree of spirometric airflow obstruction and the presence or absence of chronic bacterial colonisation.

iii) LCI is repeatable in patients with non-CF bronchiectasis, and is superior to spirometry for distinguishing between patients with non-CF bronchiectasis and healthy controls.

\section{Methods}

\section{Subjects}

Forty-three adult patients with non-CF bronchiectasis were recruited from the respiratory out-patient clinics at Glenfield Hospital. Bronchiectasis was diagnosed by high resolution computed tomography, and all scans were reported by a Consultant Radiologist to confirm the diagnosis. Eighteen healthy non-smoking control subjects with no history of respiratory symptoms were recruited through local advertising. The study was approved by the National Research Ethics Committee (East Midlands - Leicester), and all participants gave their written informed consent. As a disease comparator group, MBW data from 40 adults with CF who took part in a previous observational study [7] were re-analysed. This study was approved by the Lothian Research and Ethics Committee and all participants gave their written informed consent.

\section{Clinical characterisation of bronchiectasis patients}

Demographic details and a full medical history were obtained from each patient. Sputum samples were obtained for bacterial culture, and sputum culture results during the previous year were recorded to assess for chronic bacterial colonisation, defined as isolation of the same microorganism on sputum culture on at least two occasions during the previous year. Participants underwent spirometry and measurement of lung volumes using helium dilution according to American Thoracic Society/ European Respiratory Society guidelines [20,21].

\section{Multiple breath washout test}

MBW was performed in triplicate at a single visit, using the method described by Horsley et al. [7]. Participants wore a nose clip and breathed a known concentration $(0.2 \%)$ of an inert and non-absorbed gas, sulphur hexafluoride $\left(\mathrm{SF}_{6}\right)$, via a mouthpiece connected to an Innocor 
photoacoustic gas analyser (Innovision AS, Odense, Denmark), until the expired concentration in their exhaled breath reached a steady state (wash-in phase). Participants with non-CF bronchiectasis maintained a steady respiratory rate of approximately 12 breaths per minute, and a constant tidal volume of $1 \mathrm{~L}$, using a real-time visual display of inspired volume as a guide. Patients with CF in the previously published cohort [7] were not generally able to follow this protocol, and washout tests were therefore performed during relaxed tidal breathing in this group. Following completion of wash-in, participants were rapidly switched to breathing room air during expiration and continued the same pattern of breathing (washout phase). Washout continued until the end-tidal concentration of expired $\mathrm{SF}_{6}$ fell below $1 / 40$ th of the original concentration (ie. $<0.005 \%$ ) for three consecutive breaths.

\section{Analysis of washout curves}

Washout curves were analysed using custom software written with TestPoint (Measurement Computing Corporation, Norton, Massachusetts, USA). FRC was calculated by dividing the total volume of $\mathrm{SF}_{6}$ expired during the washout by the difference between the $\mathrm{SF}_{6}$ concentrations at the beginning and end of the washout period [22]. LCI was calculated as the cumulative expired volume at the point where the end-tidal concentration of expired $\mathrm{SF}_{6}$ fell below 1/40th of the original concentration, divided by the FRC [9]. $\mathrm{S}_{\text {cond }} /$ $\mathrm{S}_{\text {acin }}$ and $\mathrm{S}_{\text {cond }}{ }^{*} / \mathrm{S}_{\text {acin }}{ }^{*}$ were calculated as described by Verbanck et al. [16,19]. The derivation of the novel parameters $\mathrm{LCI}_{\mathrm{vent}}$ and $\mathrm{LCI}_{\mathrm{ds}}$ is described in detail in the Additional files 1,2,3,4,5,6,7 and 8. Briefly, washout curves were fitted to a theoretical two-compartment lung model. The output parameters of the model were (i) the ratio of the specific ventilations of the two compartments, and (ii) the effective respiratory dead space. These parameters were then utilised to derive:

i. LCI $_{\text {vent }}-$ The proportional increase in LCI above its ideal value due to specific ventilation inequality.

ii. $\mathrm{LCI}_{\mathrm{ds}}-$ The proportional increase in $\mathrm{LCI}$ above its ideal value due to increased respiratory dead space.

Table 1 summarises the MBW parameters calculated in this study and their physiological interpretation.

\section{Statistical analysis}

Statistical analyses were performed using SPSS Version 20 (IBM Corporation, Somers, New York, USA) and Prism 6 (GraphPad Software Inc., La Jolla, California, USA). Between-group comparisons were performed using Student's $T$ test or one-way analysis of variance for continuous data and the Chi-squared test for proportions, with the threshold for statistical significance set at $\mathrm{p}<0.05$. Repeatability of MBW parameters was
Table 1 Multiple breath washout parameters

\begin{tabular}{lll}
\hline Method of calculation & $\begin{array}{l}\text { Mechanism of ventilation } \\
\text { heterogeneity }\end{array}$ \\
\hline $\mathrm{LCl}$ & $\begin{array}{l}\text { Analysis of basic washout } \\
\text { curve }\end{array}$ & $\begin{array}{l}\text { Summary measure of overall } \\
\text { ventilation heterogeneity }\end{array}$ \\
$\mathrm{LCI}_{\text {vent }}$ & Two-compartment model & $\begin{array}{l}\text { Specific ventilation inequality: } \\
\text { convection-dependent }\end{array}$ \\
$\mathrm{LCl}_{\mathrm{ds}}$ & Two-compartment model & $\begin{array}{l}\text { Dead space contribution: } \\
\text { diffusion-convection-dependent }\end{array}$ \\
$\mathrm{S}_{\text {cond }} \quad$ Phase III slope analysis & $\begin{array}{l}\text { Convection-dependent } \\
\mathrm{S}_{\text {acin }} \quad \text { Phase III slope analysis }\end{array}$ & $\begin{array}{l}\text { Diffusion-convection- } \\
\text { dependent } \\
\text { Convection-dependent }\end{array}$ \\
$\mathrm{S}_{\text {cond }}{ }^{*}$ & $\begin{array}{l}\text { Phase III slope analysis } \\
\text { (modified) }\end{array}$ & $\begin{array}{l}\text { Diffusion-convection- } \\
\text { dependent }\end{array}$ \\
$\mathrm{S}_{\text {acin }}{ }^{*}$ & $\begin{array}{l}\text { Phase III slope analysis } \\
\text { (modified) }\end{array}$ \\
\hline
\end{tabular}

assessed using the intraclass correlation coefficient (ICC) across triplicate measurements, using a twoway mixed model. Correlations between variables were assessed using Pearson's correlation coefficient (R). A generalised linear model was used to assess whether the relationship between LCI and spirometric airflow obstruction differed between the two disease groups. Areas under receiver operating characteristic (ROC) curves were used to assess the discriminatory ability of physiological parameters.

\section{Results}

\section{Clinical characteristics}

The cohort of patients with non-CF bronchiectasis comprised 19 men and 24 women with a mean (standard deviation [SD]) age of 67.4 (7.3) years. The group included 25 never smokers, 17 ex-smokers and 1 current smoker. The median (range) pack-year smoking history of the ex- and current smokers was $17.5(1-140)$. Out of the 43 patients, a previous history of tuberculosis was elicited in 2 patients, childhood pneumonia in 14 patients and pertussis in 22 patients. Eleven patients had a history of asthma, and four had a formal diagnosis of allergic bronchopulmonary aspergillosis. Nineteen patients had symptoms of gastroesophageal reflux disease and two had inflammatory bowel disease. Twelve patients had an inflammatory arthritis and one had yellow nail syndrome. Twelve patients were chronically colonised with Haemophilus influenzae, three patients with Pseudomonas aeruginosa, two patients with Staphylococcus aureus and two patients with coliforms.

The CF group comprised 20 men and 20 women with a mean (SD) age of 28.7 (9.8) years. Three CF patients were ex-smokers (pack-year histories of 5, 15 and 24 years). Fifteen patients had chronic Pseudomonas aeruginosa colonisation as defined by Lee et al. [23], 29 had 
pancreatic insufficiency and 6 had diabetes mellitus. Nineteen patients had a severe genotype, defined as having a class I or II mutation on both chromosomes, and 16 had a mild genotype, defined as having a class III, IV or $\mathrm{V}$ mutation on at least one chromosome. The genotype was incomplete in 5 patients.

\section{Group comparisons}

Table 2 shows physiological data across all three groups. Patients with bronchiectasis and CF both displayed spirometric airflow obstruction, with significantly reduced forced expiratory volume in one second/forced vital capacity $\left(\mathrm{FEV}_{1} / \mathrm{FVC}\right)$ ratio compared to healthy controls. $\mathrm{LCI}, \mathrm{LCI}_{\mathrm{vent}}$ and $\mathrm{LCI}_{\mathrm{ds}}$ were all significantly greater in bronchiectasis patients compared to controls, and significantly greater in CF patients compared to both controls and bronchiectasis patients (see Figure 1).

\section{Correlations between spirometric airflow obstruction and lung clearance index}

Figure 2 shows correlations between the $\mathrm{FEV}_{1}$ (\% pred.) and LCI in patients with bronchiectasis and patients with CF. In both cases, there was a highly significant $(\mathrm{p}<0.0001)$ negative correlation between $\mathrm{FEV}_{1}$ (\% pred.)

Table 2 Demographic and physiological data across groups

\begin{tabular}{|c|c|c|c|}
\hline & $\begin{array}{l}\text { Control } \\
\text { subjects } \\
(n=18)\end{array}$ & $\begin{array}{l}\text { CF patients } \\
(\mathrm{n}=40)\end{array}$ & $\begin{array}{l}\text { Non-CF } \\
\text { bronchiectasis } \\
\text { patients }(n=43)\end{array}$ \\
\hline Age (years) $^{\neq \neq \neq \neq}$ & $48.3(3.9)$ & $3.7(1.5)^{\# \# \# \# ~}$ & 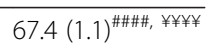 \\
\hline Sex (\% male) & 50 & 50 & 44 \\
\hline BMI $\left(\mathrm{kg} / \mathrm{m}^{2}\right)^{\ddagger \neq \neq \neq}$ & $26.8(1.2)$ & $22.9(0.5)^{\# \#}$ & $27.1(0.7)^{¥ \neq ¥ \neq}$ \\
\hline $\mathrm{FEV}_{1}(\% \text { pred. })^{\ddagger \neq \neq \neq}$ & $113.3(4.8)$ & $65.9(3.4)^{\# \# \# \#}$ & 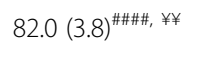 \\
\hline FVC (\% pred. $)^{\ddagger \neq \neq \neq}$ & $117.2(5.6)$ & $84.5(3.0)^{\# \# \# \#}$ & $96.1(3.4)^{\# \#, ~ ¥ ~}$ \\
\hline $\mathrm{FEV}_{1} / \mathrm{FVC}(\%)^{\ddagger \neq \neq \neq \neq}$ & $80.9(1.0)$ & $65.9(1.8)^{\# \# \# \#}$ & $68.4(1.7)^{\# \# \# \#}$ \\
\hline$F R C_{m b w}(L)^{\ddagger \neq}$ & $2.52(0.19)$ & $1.99(0.09)^{\#}$ & $2.48(0.10)^{¥ ¥}$ \\
\hline $\mathrm{LCl}^{\neq \neq \neq \neq}$ & $7.28(0.27)$ & $13.17(0.56)^{\# \# \# \#}$ & $9.99(0.31)^{\# \#, ¥ ¥ ¥ \neq}$ \\
\hline $\mathrm{LCl}_{\text {vent }}{ }^{\neq \neq \neq \neq}$ & $1.20(0.02)$ & 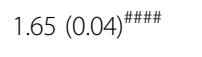 & $1.42(0.03)^{\# \# \#, ¥ ¥ ¥ ¥}$ \\
\hline $\mathrm{LCl}_{\mathrm{ds}}{ }^{\neq \neq \neq \neq}$ & $1.13(0.01)$ & 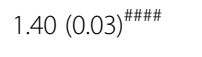 & $1.27(0.02)^{\# \# \#, ¥ ¥ ¥ ¥}$ \\
\hline$S_{\text {cond }}\left(L^{-1}\right)^{\ddagger \neq \neq \neq}$ & $0.033(0.007)$ & $0.131(0.010)^{\# \# \# \#}$ & $0.064(0.007)^{¥ \neq ¥ \neq}$ \\
\hline$S_{\text {acin }}\left(L^{-1}\right)^{\ddagger \neq \neq \neq}$ & $0.118(0.014)$ & $0.509(0.056)^{\# \# \# \#}$ & $0.373(0.036)^{\# \#}$ \\
\hline 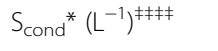 & $0.097(0.009)$ & $0.308(0.034)^{\# \# \# \#}$ & $0.107(0.010)^{¥ \neq ¥ \neq}$ \\
\hline $\operatorname{Sacin}^{*}\left(L^{-1}\right)^{\ddagger \neq \neq \neq}$ & $0.090(0.012)$ & $0.446(0.054)^{\# \# \# \#}$ & $0.355(0.037)^{\# \#}$ \\
\hline
\end{tabular}

$\mathrm{CF}=$ cystic fibrosis; $\mathrm{BMI}=$ body mass index; $\mathrm{FEV}_{1}=$ forced expiratory volume in one second; $F V C=$ forced vital capacity; $F R C_{m b w}=$ functional residual capacity from multiple breath washout; $\mathrm{LCl}=$ lung clearance index; $\mathrm{LCl}_{\text {vent }}=$ specific ventilation inequality component of lung clearance index; $\mathrm{LCl}_{\mathrm{ds}}=$ dead space component of lung clearance index. Data expressed as mean (standard error) or percentages. Groups compared using one-way analysis of variance with Bonferroni correction for multiple comparisons for parametric data, and the Chi-squared test for proportions. Significant differences across groups denoted ${ }^{\ddagger \ddagger}(p<0.01)$ or ${ }^{\ddagger \neq \neq \ddagger}(p<0.0001)$. Significant differences compared to control

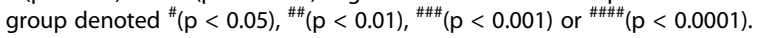
Significant differences between bronchiectasis and CF groups denoted

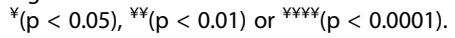

and LCI. However, the slope of the relationship between the two variables differed significantly between the groups. Patients with CF had a 0.13 unit increase in LCI for every 1 percentage point reduction in $\mathrm{FEV}_{1}$ (\% pred.), whereas patients with bronchiectasis had a 0.05 unit increase in LCI for every 1 percentage point reduction in $\mathrm{FEV}_{1}$ (\% pred.) ( $\left.\mathrm{p}<0.0001\right)$. $\mathrm{LCI}_{\mathrm{vent}}$ and $\mathrm{LCI}_{\mathrm{ds}}$ correlated highly significantly with $\mathrm{FEV}_{1}$ (\% pred.) in both patients with non-CF bronchiectasis $(R=-0.63$ for $\mathrm{LCI}_{\text {vent }}, \mathrm{R}=-0.60$ for $\mathrm{LCI}_{\mathrm{ds}}, \mathrm{p}<0.0001$ for both analyses) and patients with $\mathrm{CF}\left(\mathrm{R}=-0.78\right.$ for $\mathrm{LCI}_{\mathrm{vent}}$, $\mathrm{R}=-0.76$ for $\mathrm{LCI}_{\mathrm{ds}}, \mathrm{p}<0.0001$ for both analyses). There were significant correlations between $\mathrm{LCI}_{\text {vent }}$ and $\mathrm{LCI}_{\mathrm{ds}}$ in both patient groups $(\mathrm{R}=0.80, \mathrm{p}<0.0001$ for non-CF bronchiectasis; $\mathrm{R}=0.89, \mathrm{p}<0.0001$ for $\mathrm{CF}$ ).

\section{Multiple breath washout parameters and chronic bacterial colonisation}

Table 3 shows MBW and spirometric indices in patients with $\mathrm{CF}$ in the presence and absence of chronic P. aeruginosa colonisation, and in patients with non-CF bronchiectasis in the presence and absence of chronic bacterial colonisation. $\mathrm{LCI}_{\mathrm{ds}}$ was significantly raised in $\mathrm{CF}$ patients with chronic $P$. aeruginosa colonisation compared to those without chronic colonisation (1.49 vs $1.34, \mathrm{p}=0.004)$.

\section{Within-visit repeatability and discriminatory ability}

Table 4 shows the repeatability of MBW parameters in patients with bronchiectasis and CF. Intraclass correlation coefficients exceeded 0.75 for $\mathrm{LCI}, \mathrm{LCI}_{\mathrm{vent}}$ and $\mathrm{LCI}_{\mathrm{ds}}$ in both disease groups. $\mathrm{S}_{\mathrm{acin}}$ and $\mathrm{S}_{\mathrm{acin}}{ }^{*}$ displayed moderate or good repeatability, but $\mathrm{S}_{\text {cond }}$ and $\mathrm{S}_{\text {cond }}{ }^{*}$ were poorly repeatable in both disease groups. Figure 3 shows ROC curves illustrating the discriminatory ability of $\mathrm{LCI}$ and $\mathrm{FEV}_{1}$ (\% pred.) for distinguishing between healthy controls and patients with non-CF bronchiectasis. The area under the ROC curve was 0.90 for LCI and 0.83 for $\mathrm{FEV}_{1}$ (\% pred.). Areas under the ROC curve for $\mathrm{LCI}_{\mathrm{vent}}$ and $\mathrm{LCI}_{\mathrm{ds}}$ were 0.88 and 0.89 , respectively.

Figure 4 shows graphs of $\mathrm{FEV}_{1}$ standardised residuals against $\mathrm{LCI}, \mathrm{LCI}_{\mathrm{vent}}$ and $\mathrm{LCI}_{\mathrm{ds}}$ in patients with non-CF bronchiectasis. The lower limit of normal for $\mathrm{FEV}_{1}$ was defined as 1.645 standard deviations below the predicted value, while the upper limits of normal for $\mathrm{LCI}, \mathrm{LCI}_{\text {vent }}$ and $\mathrm{LCI}_{\mathrm{ds}}$ were defined as the mean +1.645 standard deviations in the healthy control group. Thirty out of 43 patients had an $\mathrm{FEV}_{1}$ within the normal range, and of these, $\mathrm{LCI}, \mathrm{LCI}_{\text {vent }}$ and $\mathrm{LCI}_{\mathrm{ds}}$ were high in 12,10 and 10 patients, respectively. Conversely, there were no patients who had an $\mathrm{FEV}_{1}$ below the normal range who did not also have a raised LCI and $\mathrm{LCI}_{\text {vent, }}$ and only one patient who had an $\mathrm{FEV}_{1}$ below the normal range with a normal $\mathrm{LCI}_{\mathrm{ds}}$. 


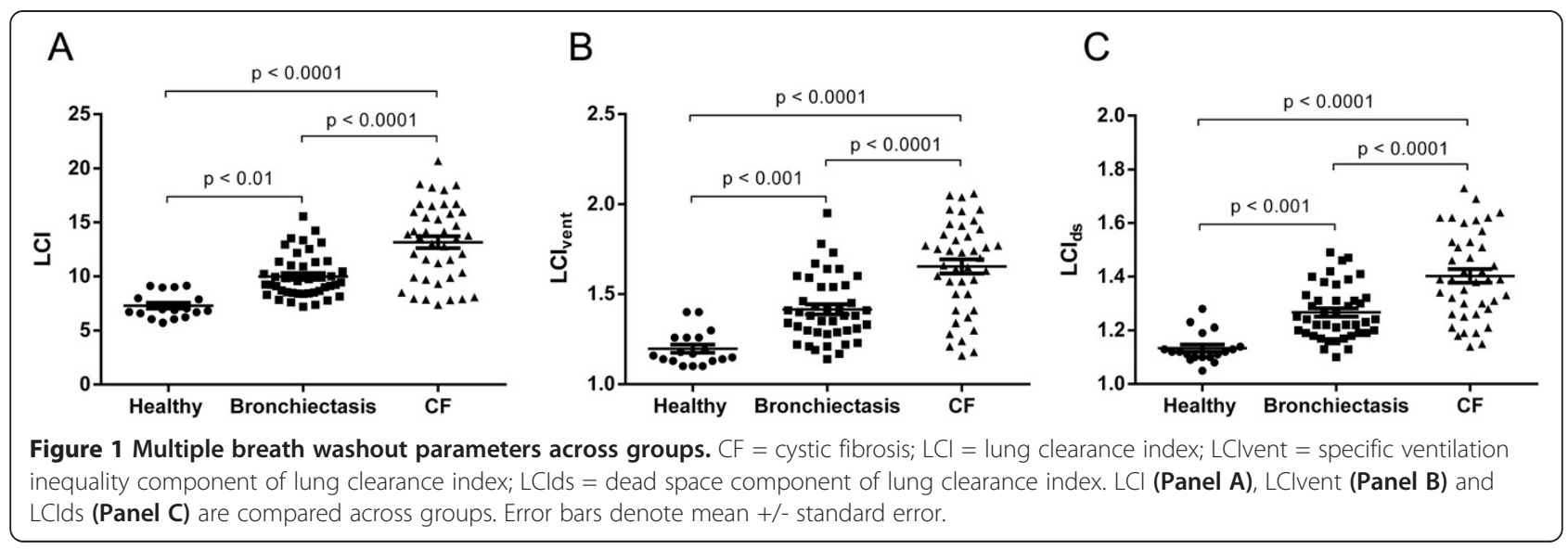

\section{Discussion}

We have shown that $\mathrm{LCI}$, and the novel parameters $\mathrm{LCI}_{\text {vent }}$ and $\mathrm{LCI}_{\mathrm{ds}}$, are significantly raised in patients with non-CF bronchiectasis compared to controls, and that these parameters correlate strongly with spirometric markers of airflow obstruction. $\mathrm{LCI}, \mathrm{LCI}_{\mathrm{vent}}$ and $\mathrm{LCI}_{\mathrm{ds}}$ display good within-visit repeatability in patients with non-CF bronchiectasis, and superior discriminatory ability for distinguishing bronchiectasis patients from controls compared to $\mathrm{FEV}_{1}$. Moreover, these parameters are abnormally raised in a significant proportion of non-CF bronchiectasis patients with a normal $\mathrm{FEV}_{1}$. These findings suggest that MBW parameters may have potential as markers of disease severity in patients with non-CF bronchiectasis, and may be indicators of incipient airflow obstruction, although longitudinal studies are required to test this hypothesis. Further studies are also required to determine the between-visit variability and minimal clinically important difference of MBW parameters in patients with non-CF bronchiectasis, as well as their responsiveness to therapeutic interventions.
A major aim of this study was to develop novel markers of ventilation heterogeneity that would distinguish between the two possible mechanisms of increased LCI, namely specific ventilation inequality and increased respiratory dead space. Previous studies have used measures of the curvilinearity of the washout curve as markers of specific ventilation inequality, but these methods did not provide a formal estimate of the respiratory dead space component $[15,19]$. Although in healthy subjects it is thought that specific ventilation inequality is the only mechanism of ventilation heterogeneity operative at the level of the proximal conducting airways, the situation is disease is far more complex. Depending on the extent of airway damage and obstruction, diffusion may not be neatly compartmentalised to the distal airways. An advantage of the current method is that it does not pre-suppose an anatomical location for the observed abnormalities in ventilation heterogeneity, but concentrates on the underlying mechanisms. This is particularly relevant when dealing with those with more severe airflow

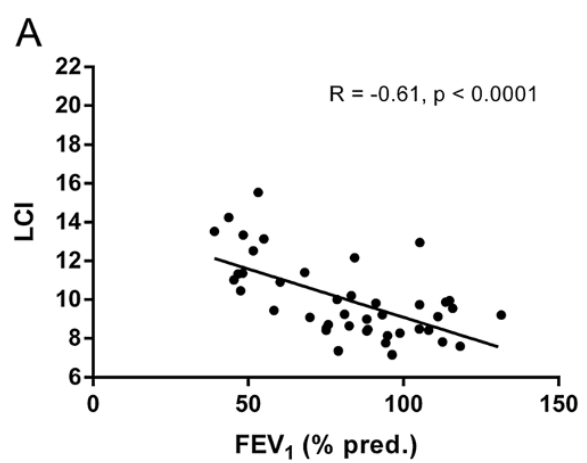

B

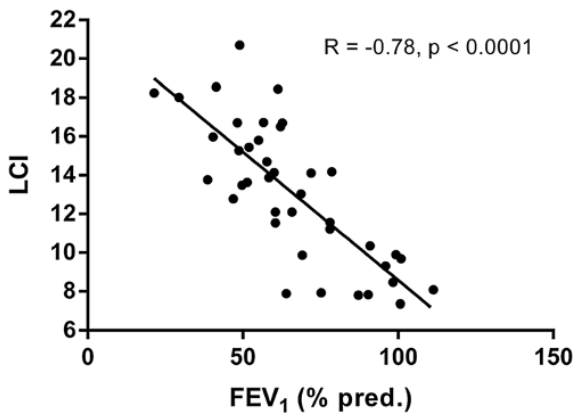

Figure 2 Correlations between lung clearance index and $\mathrm{FEV}_{\mathbf{1}}$ (\% predicted). Correlations are shown for patients with non-cystic fibrosis bronchiectasis (Panel A) and cystic fibrosis (Panel B). $\mathrm{LCl}=$ lung clearance index; FEV ${ }_{1}=$ forced expiratory volume in one second. Best-fit linear regression lines are shown, together with Pearson correlation coefficients. 
Table 3 Physiological parameters in patients with and without chronic bacterial colonisation

\begin{tabular}{|c|c|c|c|c|}
\hline & \multicolumn{2}{|c|}{ Non-cystic fibrosis bronchiectasis } & \multicolumn{2}{|l|}{ Cystic fibrosis } \\
\hline & $\begin{array}{l}\text { No chronic colonisation } \\
(n=26)\end{array}$ & $\begin{array}{l}\text { Chronic colonisation } \\
(n=17)\end{array}$ & $\begin{array}{l}\text { No chronic PsA colonisation } \\
(n=25)\end{array}$ & $\begin{array}{l}\text { Chronic PsA colonisation } \\
(n=15)\end{array}$ \\
\hline $\mathrm{FEV}_{1}(\%$ pred.) & $86.1(5.3)$ & $75.6(4.9)$ & $69.7(4.5)$ & $59.6(4.5)$ \\
\hline FVC (\% pred.) & $101.7(4.6)$ & $87.5(4.1)^{\#}$ & $86.9(3.6)$ & $80.6(5.5)$ \\
\hline $\mathrm{FEV}_{1} / \mathrm{FVC}(\%)$ & $68.6(2.4)$ & $68.1(2.4)$ & $67.1(2.5)$ & $63.9(2.5)$ \\
\hline TLC (\% pred.) & $95.3(3.1)$ & $93.9(4.0)$ & - & - \\
\hline $\mathrm{LCl}$ & $10.02(0.36)$ & $9.95(0.57)$ & $12.29(0.72)$ & $14.44(0.85)$ \\
\hline $\mathrm{LCI}_{\text {vent }}$ & $1.42(0.03)$ & $1.41(0.05)$ & $1.59(0.05)$ & $1.75(0.05)$ \\
\hline $\mathrm{LCl}_{\mathrm{ds}}$ & $1.27(0.02)$ & $1.26(0.03)$ & $1.34(0.03)$ & $1.49(0.04)^{\# \#}$ \\
\hline$S_{\text {cond }}\left(L^{-1}\right)$ & $0.058(0.010)$ & $0.072(0.010)$ & $0.122(0.010)$ & $0.132(0.018)$ \\
\hline $\mathrm{S}_{\text {acin }}\left(\mathrm{L}^{-1}\right)$ & $0.429(0.053)$ & $0.288(0.038)$ & $0.438(0.070)$ & $0.611(0.093)$ \\
\hline $\mathrm{S}_{\text {cond }^{*}\left(\mathrm{~L}^{-1}\right)}$ & $0.102(0.014)$ & $0.115(0.016)$ & $0.284(0.034)$ & $0.294(0.051)$ \\
\hline $\mathrm{S}_{\text {acin }}{ }^{*}\left(\mathrm{~L}^{-1}\right)$ & $0.412(0.053)$ & $0.268(0.041)$ & $0.376(0.068)$ & $0.553(0.092)$ \\
\hline
\end{tabular}

PsA = Pseudomonas aeruginosa; $\mathrm{FEV}_{1}=$ forced expiratory volume in one second; $\mathrm{FVC}=$ forced vital capacity; $\mathrm{TLC}=$ total lung capacity; $\mathrm{LCl}=$ lung clearance index; $\mathrm{LCl}_{\text {vent }}=$ specific ventilation inequality component of lung clearance index; $\mathrm{LCl}_{\mathrm{ds}}=$ dead space component of lung clearance index. Data expressed as mean (standard error). Colonised and non-colonised groups within each disease cohort compared using Student's $T$ test. Significant differences between groups denoted $\#(p<0.05)$ or ${ }^{\# \#}(p<0.01)$.

obstruction and ventilation heterogeneity. Furthermore, since the proximal and distal airways are not independent of each other, and form a complex interacting network [24], it is also unsurprising that we noted a correlation between $\mathrm{LCI}_{\text {vent }}$ and $\mathrm{LCI}_{\mathrm{ds}}$ in both patient groups. $\mathrm{LCI}_{\mathrm{vent}}$ and $\mathrm{LCI}_{\mathrm{ds}}$ may however allow subtle distinctions to be made in terms of mechanisms of disease in airway diseases such as $\mathrm{CF}$ and non-CF bronchiectasis. Indeed, we observed that $\mathrm{CF}$ patients with chronic $P$. aeruginosa colonisation had increased $\mathrm{LCI}_{\mathrm{ds}}$ compared to those who did not, whereas $\mathrm{LCI}_{\text {vent }}$ did not differ significantly between the groups. This extends the findings of Belessis et al. [25], who observed that LCI was higher in children with CF who

Table 4 Within-visit repeatability of multiple breath washout parameters

\begin{tabular}{lcc}
\hline & ICC in non-CF bronchiectasis & ICC in CF \\
\hline $\mathrm{LCl}$ & 0.86 & 0.93 \\
$\mathrm{LCl}_{\text {vent }}$ & 0.91 & 0.89 \\
$\mathrm{LCl}_{\mathrm{ds}}$ & 0.79 & 0.88 \\
$\mathrm{~S}_{\text {cond }}$ & 0.15 & 0.19 \\
$\mathrm{~S}_{\text {acin }}$ & 0.63 & 0.88 \\
$\mathrm{~S}_{\text {cond }}{ }^{*}$ & 0.10 & 0.41 \\
$\mathrm{~S}_{\text {acin }}{ }^{*}$ & 0.65 & 0.90 \\
\hline $\mathrm{CC}=$
\end{tabular}

$\mathrm{ICC}=$ intraclass correlation coefficient; $\mathrm{SD}=$ standard deviation; $\mathrm{CF}=$ cystic fibrosis; $\mathrm{LCl}=$ lung clearance index; $\mathrm{LCl}_{\text {vent }}=$ specific ventilation inequality component of lung clearance index; $\mathrm{LCl}_{\mathrm{ds}}=$ dead space component of lung clearance index. had $P$. aeruginosa colonisation compared to those who did not. Our results suggest that this increase in LCI may be driven predominantly by an increased respiratory dead space. Interestingly, neither MBW parameters nor $\mathrm{FEV}_{1}$ (\% pred.) differed significantly between non-CF bronchiectasis patients with and without chronic bacterial colonisation. Chronic colonisation in our cohort was mainly with $H$. influenzae rather than $P$. aeruginosa, and our data therefore concord with previous observations that $H$. influenzae, unlike $P$. aeruginosa, is not associated with faster lung function decline in non-CF bronchiectasis [26]. The reduced FVC (\% pred.) we observed in non-CF bronchiectasis patients with chronic colonisation was not associated with an abnormally low TLC (\% pred.), and therefore did not represent a true restrictive deficit.

Previous attempts to apply phase III slope analysis in $\mathrm{CF}$ were less successful than in reports from other disease groups, because of both poor repeatability and reliance of the original method on a strict $1 \mathrm{~L}$ breathing protocol [18]. Although it relies on a relaxed and repeatable breathing pattern, the current method does not require strict breath volume control, something patients often find harder to maintain than well-trained volunteers. In addition, $\mathrm{LCI}_{\text {vent }}$ and $\mathrm{LCI}_{\mathrm{ds}}$ showed superior repeatability to phase III slope parameters, in particular to $\mathrm{S}_{\text {cond }}$ and $\mathrm{S}_{\text {cond }}{ }^{*}$. This is an important attribute if these measures are to be used to assess change over time, or in response to therapeutic intervention.

A potential limitation of our study was that the disease groups were not matched for age with the control group. 

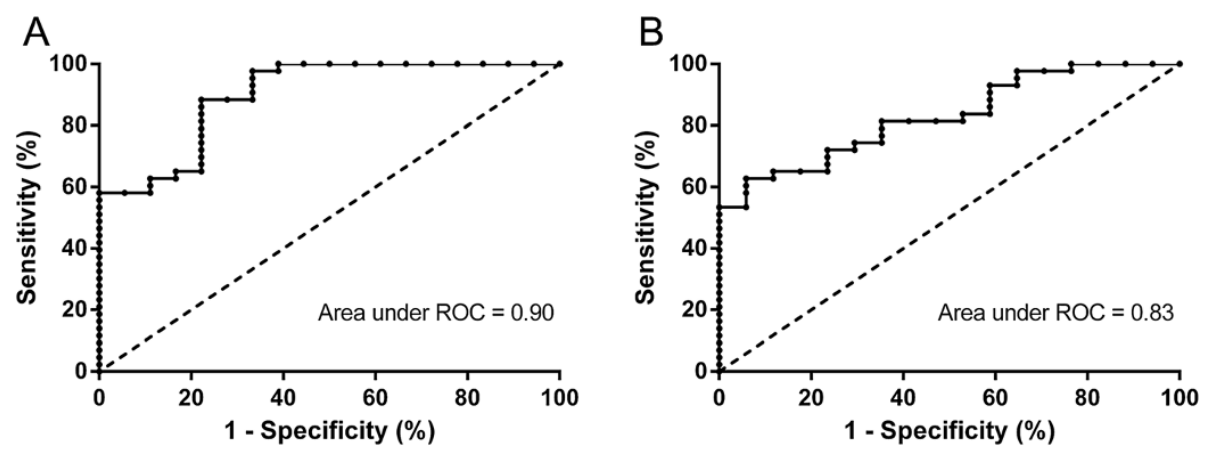

Figure 3 Receiver operating characteristic curves of lung clearance index and $\mathrm{FEV}_{1}$ (\% pred.) for distinguishing between control subjects and bronchiectasis patients. Receiver operating characteristic (ROC) curves are shown for lung clearance index (LCI) (Panel A) and forced expiratory volume in one second percent predicted (FEV 1 [\% pred.]) (Panel B). Areas under ROC curves are 0.90 for $\mathrm{LCl}_{\text {and }} 0.83$ for FEV ${ }_{1}$ (\% pred.).

This was to a certain extent unavoidable, since patients with non-CF bronchiectasis are in general older than those with CF, and we therefore chose our control group to be approximately intermediate in age between the two disease groups. However, recently published regression equations [27] indicate that the effects of this on our results were likely to be modest - in particular, LCI is expected to increase by 0.0223 units per year, so the 19-year difference in mean age between patients with bronchiectasis and healthy controls would be predicted to cause a relatively small 0.43 difference in LCI between the groups. Furthermore, the upper limit of normal of LCI derived from our healthy control data was slightly higher than that reported in previous studies using the same methodology [7], a difference that may be explained by the older age of our healthy cohort. Further studies are required to derive age- and sex-dependent normative ranges for $\mathrm{LCI}$ using the $\mathrm{SF}_{6}$ wash-in method, as have been published for nitrogen washout [27].

In conclusion, we have shown that LCI, a marker of impaired gas mixing derived from the MBW test, is significantly raised in patients with non-CF bronchiectasis, and that this elevation correlates with spirometric airflow obstruction. LCI is repeatable and discriminatory in patients with non-CF bronchiectasis, and future studies are now required to assess the prognostic significance of a raised LCI in this patient group, as well as the potential utility of this marker as an outcome measure in interventional trials. The novel parameters $\mathrm{LCI}_{\mathrm{vent}}$ and $\mathrm{LCI}_{\mathrm{ds}}$ are a practical and repeatable alternative to phase III slope analysis and may allow a further level of mechanistic information to be obtained from the MBW test without any additional demand on the patient. They should be reported in conjunction with LCI in future observational and interventional studies that incorporate the MBW technique.
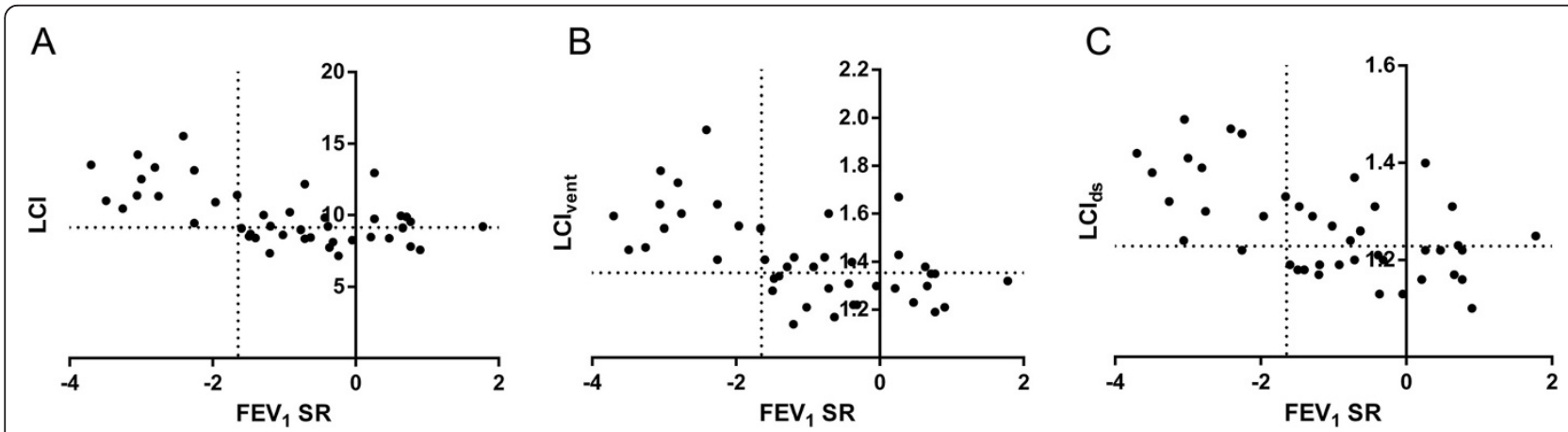

Figure 4 Scatterplots of forced expiratory volume in one second standardised residuals against multiple breath washout parameters. $\mathrm{LCl}=$ lung clearance index; $\mathrm{LClvent}=$ specific ventilation inequality component of lung clearance index; $L C l d s=$ dead space component of lung clearance index; FEV1 = forced expiratory volume in one second; SR = standardised residuals. FEV1 SR are plotted against LCI (Panel A), LClvent (Panel B) and LClds (Panel C). Dotted lines denote the lower limit of normal for FEV1 and upper limits of normal for $\mathrm{LCl}$, LClvent and LClds. 


\section{Additional files}

\section{Additional file 1: Derivation of the indices LClvent and LClds} (Additional files 2, 3, 4, 5, 6, 7 and 8).

Additional file 2: Figure E1. Washout curve from a healthy subject. $C_{\mathrm{et}}=$ end-tidal $\mathrm{SF}_{6}$ concentration; $\mathrm{TO}=$ turnover number.

Additional file 3: Figure E2. Simulated washout curves with varying specific ventilation inequality and effective respiratory dead space. $C_{\mathrm{et}}=$ end-tidal $\mathrm{SF}_{6}$ concentration; $\mathrm{TO}=$ turnover number. Panel A shows simulated washout curves with low (continuous line), intermediate (dashed line) and high (dotted line) levels of specific ventilation inequality. Panel B shows simulated washout curves with small (continuous line), intermediate (dashed line) and large (dotted line) effective respiratory dead space.

Additional file 4: Figure E3. One-compartment lung model. $\mathrm{VD}_{\text {anat }}=$ anatomical dead space; $V T=$ tidal volume; $V A=$ alveolar volume; $F R C=$ functional residual capacity.

Additional file 5: Figure E4. Exponential decay curves. Single exponential decay curves of the form $y=0.2 \times e^{-k x}$ are shown with rate constants $(k)$ of 0.2 (dotted line), 0.6 (dashed line) and 1.8 (continuous line).

Additional file 6: Figure E5. Washout curves from a healthy subject and a patient with cystic fibrosis fitted to a one-phase exponential decay model. $\mathrm{C}_{\text {et }(\text { norm) }}=$ normalised end-tidal $\mathrm{SF}_{6}$ concentration; $\mathrm{TO}=$ turnover number. Panels $A$ and $B$ show washout curves from a healthy subject and a patient with cystic fibrosis, respectively, fitted to a one-phase exponential decay model.

Additional file 7: Figure E6. Washout curves from a healthy subject and a patient with cystic fibrosis fitted to a two-phase exponential decay model. $\mathrm{C}_{\text {et }(\text { norm })}=$ normalised end-tidal $\mathrm{SF}_{6}$ concentration; $\mathrm{TO}=$ turnover number. Panels $A$ and $B$ show washout curves from a healthy subject and a patient with cystic fibrosis, respectively, fitted to a two-phase exponential decay model. Goodness of fit $\left(R^{2}\right)=0.9973$ for healthy subject and 0.9775 for cystic fibrosis patient.

Additional file 8: Figure E7. Two-compartment lung model. $V_{\text {slow }}=$ volume of under-ventilated (slow) lung unit; $V_{\text {fast }}=$ volume of over-ventilated (fast) lung unit; $V T=$ tidal volume; $c=$ proportion of tidal volume reaching fast lung unit.

\section{Competing interests}

CEB has received grant funding from Roche-Genentech, Novartis, AZMedlmmune, Chiesi and GSK; consultancy fees from Hoffmann-La Roche, AZ, GSK, Novartis, Chiesi and Merck; and funding for travel to scientific meetings from Boehringer Ingelheim. SS has received research grants from Chiesi to study small airway microstructure and has received lecturing fees from Chiesi and GSK and consultancy fees from Teva. SG has received funding for travel to scientific meetings from GSK and Chiesi. AH has received a grant from the National Institute for Health Research to investigate lung clearance index. Part of this involves a collaboration with Innovision ApS, the manufacturers of the Innocor gas analyser used in the study. IP has received speaker's fees, honoraria for attending advisory boards and travel expenses from GSK, $A Z$, Boehringer Ingelheim, Napp, Novartis, Aerocrine and Boston Scientific. A Scadding, MS, A Singapuri, PG, SR and CO have no conflicts of interest to declare.

\section{Authors' contributions}

SG - Analysed washout curves, derived novel indices, performed statistical analysis of the data and wrote the manuscript. A Scadding - Recruited patients, characterised them clinically, and performed washout tests. MS Performed washout tests. A Singapuri - Recruited patients and performed washout tests. PG - Assisted with setting up the inert gas washout system, and critically appraised the manuscript. CO - Recruited patients and critically appraised the manuscript. SR - Recruited patients and critically appraised the manuscript. CEB - Involved in study conception and design, and critically appraised the manuscript. IP - Involved in study conception and design, and critically appraised the manuscript. $\mathrm{AH}$ - Involved in study conception and design, and supervised the writing of the manuscript. SS - Involved in study conception and design, and supervised the writing of the manuscript. All authors read and approved the final manuscript.
Authors' information

Alex Horsley and Salman Siddiqui are co-senior authors.

\section{Acknowledgements}

This paper was supported by the National Institute for Health Research (NIHR) Leicester Respiratory Biomedical Research Unit. The views expressed are those of the author(s) and not necessarily those of the NHS, the NIHR or the Department of Health. This work was partly funded by grants-in-aid from Chiesi Farmaceutici S. P. A. Additional funding was received from the Airway Disease PRedicting Outcomes through Patient Specific Computational Modelling (AirPROM) project (funded through an FP7 European Union grant). Data from cystic fibrosis patients were collected as part of a separate research project funded by the CF Trust through the UK CF Gene Therapy Consortium.

\section{Author details}

${ }^{1}$ Institute for Lung Health, University of Leicester, Leicester, UK. ${ }^{2}$ Department of Paediatrics, Central Hospital, Skövde, Sweden. ${ }^{3}$ Manchester Adult Cystic Fibrosis Centre, Manchester, UK. ${ }^{4}$ Institute of Inflammation and Repair, University of Manchester, Manchester, UK. ${ }^{5}$ Respiratory BRU, Glenfield Hospital, Groby Road, Leicester LE3 9QP, UK.

Received: 2 December 2013 Accepted: 8 May 2014

Published: 18 May 2014

\section{References}

1. Seitz AE, Olivier KN, Adjemian J, Holland SM, Prevots R: Trends in bronchiectasis among medicare beneficiaries in the United States, 2000 to 2007. Chest 2012, 142(2):432-439.

2. Weycker D, Edelsberg J, Oster G, Tino G: Prevalence and economic burden of bronchiectasis. Clin Pulm Med 2005, 12(4):205-209.

3. McShane PJ, Naureckas ET, Tino G, Strek ME: Non-cystic fibrosis bronchiectasis. Am J Respir Crit Care Med 2013, 188(6):647-656.

4. De Soyza A, Brown JS, Loebinger MR, Bronchiectasis Research \& Academic Network: Research priorities in bronchiectasis. Thorax 2013, 68(7):695-696.

5. Robinson PD, Goldman MD, Gustafsson PM: Inert gas washout: theoretical background and clinical utility in respiratory disease. Respiration 2009, 78(3):339-355.

6. Verbanck S, Schuermans D, Noppen M, Van Muylem A, Paiva M, Vincken W: Evidence of acinar airway involvement in asthma. Am J Respir Crit Care Med 1999, 159(5 Pt 1):1545-1550.

7. Horsley AR, Gustafsson PM, Macleod KA, Saunders C, Greening AP, Porteous DJ, Davies JC, Cunningham S, Alton EW, Innes JA: Lung clearance index is a sensitive, repeatable and practical measure of airways disease in adults with cystic fibrosis. Thorax 2008, 63(2):135-140.

8. Robinson P, Latzin P, Verbanck S, Hall GL, Horsley A, Gappa M, Thamrin C, Arets HG, Aurora P, Fuchs S, King GG, Lum S, Macleod K, Paiva M, Pillow J, Ranganathan S, Ratjen F, Singer F, Sonnappa S, Stocks J, Subbarao P, Thompson B, Gustafsson PM: Consensus statement for inert gas washout measurement using multiple and single breath tests. Eur Respir J 2013, 41(3):507-522

9. Bouhuys A, Lichtneckert S, Lundgren C, Lundin G: Voluntary changes in breathing pattern and N2 clearance from lungs. J Appl Physiol 1961, 16(6):1039-1042.

10. Horsley A: Lung clearance index in the assessment of airways disease. Resp Med 2009, 103(6):793-799.

11. Amin R, Subbarao P, Jabar A, Balkovec S, Jensen R, Kerrigan S, Gustafsson P, Ratjen $\mathrm{F}$ : Hypertonic saline improves the $\mathrm{LCl}$ in paediatric patients with CF with normal lung function. Thorax 2010, 65(5):379-383.

12. Amin R, Subbarao P, Lou W, Jabar A, Balkovec S, Jensen R, Kerrigan S, Gustafsson P, Ratjen F: The effect of dornase alfa on ventilation inhomogeneity in patients with cystic fibrosis. Eur Respir J 2011 37(4):806-812.

13. Horsley AR, Davies JC, Gray RD, Macleod KA, Donovan J, Aziz ZA, Bell NJ, Rainer M, Mt-Isa S, Voase N, Dewar MH, Saunders C, Gibson JS, Parra-Leiton J, Larsen MD, Jeswiet S, Soussi S, Bakar Y, Meister MG, Tyler P, Doherty A, Hansell DM, Ashby D, Hyde SC, Gill DR, Greening AP, Porteous DJ, Innes JA, Boyd AC, Griesenbach U, et al: Changes in physiological, functional and structural markers of cystic fibrosis lung disease with treatment of a pulmonary exacerbation. Thorax 2013, 68(6):532-539. 
14. Rowan SA, Bradley JM, Bradbury I, Lawson J, Lynch T, Gustafsson P, Horsley A, O'Neill K, Ennis M, Elborn JS: Lung clearance index is a repeatable and sensitive indicator of radiological changes in bronchiectasis. Am J Respir Crit Care Med 2014, 189(5):586-592.

15. Verbanck S, Paiva M, Schuermans D, Hanon S, Vincken W, Van Muylem A: Relationships between the lung clearance index and conductive and acinar ventilation heterogeneity. J Appl Physiol 2012, 112(5):782-790.

16. Verbanck S, Schuermans D, van Muylem A, Noppen M, Paiva M, Vincken W: Ventilation distribution during histamine provocation. J Appl Physiol 1997, 83(6):1907-1916.

17. Crawford AB, Makowska M, Paiva M, Engel LA: Convection- and diffusion-dependent ventilation maldistribution in normal subjects. J Appl Physiol 1985, 59(3):838-846.

18. Horsley AR, Macleod KA, Robson AG, Lenney J, Bell NJ, Cunningham S, Greening AP, Gustafsson PM, Innes JA: Effects of cystic fibrosis lung disease on gas mixing indices derived from alveolar slope analysis. Respir Physiol Neurobiol 2008, 162(3):197-203.

19. Verbanck S, Paiva M, Schuermans D, Malfroot A, Vincken W, Vanderhelst E: Acinar and conductive ventilation heterogeneity in severe CF lung disease: back to the model. Respir Physiol Neurobiol 2013, 188(2):124-132.

20. Miller MR, Hankinson J, Brusasco V, Burgos F, Casaburi R, Coates A, Crapo R, Enright $P$, van der Grinten CP, Gustafsson P, Jensen R, Johnson DC, Maclntyre N, McKay R, Navajas D, Pedersen OF, Pellegrino R, Viegi G, Wanger J, ATS/ERS Task Force: Standardisation of spirometry. Eur Respir J 2005, 26(2):319-338.

21. Wanger J, Clausen JL, Coates A, Pedersen OF, Brusasco V, Burgos F, Casaburi R, Crapo R, Enright P, van der Grinten CP, Gustafsson P, Hankinson J, Jensen R, Johnson D, Macintyre N, McKay R, Miller MR, Navajas D, Pellegrino R, Viegi G: Standardisation of the measurement of lung volumes. Eur Respir J 2005, 26(3):511-522.

22. Darling RC, Cournand A, Richards DW: Studies on the intrapulmonary mixture of gases III. An open circuit method for measuring residual air. J Clin Invest 1940, 19(4):609-618.

23. Lee TW, Brownlee KG, Conway SP, Denton M, Littlewood JM: Evaluation of a new definition for chronic Pseudomonas aeruginosa infection in cystic fibrosis patients. J Cyst Fibros 2003, 2(1):29-34.

24. Venegas JG, Winkler T, Musch G, Vidal Melo MF, Layfield D, Tgavalekos N, Fischman AJ, Callahan RJ, Bellani G, Harris RS: Self-organized patchiness in asthma as a prelude to catastrophic shifts. Nature 2005, 434(7034):777-782.

25. Belessis Y, Dixon B, Hawkins G, Pereira J, Peat J, MacDonald R, Field P, Numa A, Morton J, Lui K, Jaffe A: Early cystic fibrosis lung disease detected by bronchoalveolar lavage and lung clearance index. Am J Respir Crit Care Med 2012, 185(8):862-873.

26. Martínez-García MA, Soler-Cataluña JJ, Perpiñá-Tordera M, Román-Sánchez P, Soriano J: Factors associated with lung function decline in adult patients with stable non-cystic fibrosis bronchiectasis. Chest 2007, 132(5):1565-1572.

27. Verbanck S, Thompson BR, Schuermans D, Kalsi H, Biddiscombe M, Stuart-Andrews C, Hanon S, Van Muylem A, Paiva M, Vincken W, Usmani O: Ventilation heterogeneity in the acinar and conductive zones of the normal ageing lung. Thorax 2012, 67(9):789-795.

doi:10.1186/1465-9921-15-59

Cite this article as: Gonem et al:: Lung clearance index in adults with non-cystic fibrosis bronchiectasis. Respiratory Research 2014 15:59.

\section{Submit your next manuscript to BioMed Central and take full advantage of:}

- Convenient online submission

- Thorough peer review

- No space constraints or color figure charges

- Immediate publication on acceptance

- Inclusion in PubMed, CAS, Scopus and Google Scholar

- Research which is freely available for redistribution 